\title{
ОЦЕНКА ВЛИЯНИЯ МЕЖХОДОВЫХ ЦЕЛИКОВ НА СКОРОСТЬ ОСЕДАНИЯ ЗЕМНОЙ ПОВЕРХНОСТИ
}

\author{
П.А. ГЛЕБОВА \\ Горный институт УрО РАН, г. Пермь
}

\begin{abstract}
Аннотация: На основе математического моделирования выполнен анализ влияния межходовых целиков на степень нагружения междукамерных целиков и скорость оседания земной поверхности. Описан процесс изменения степени нагружения междукамерных целиков по мере разрушения межходовых целиков, связанный с увеличением нагрузки и расчетной высоты. Представлены результаты расчетов при различных вариантах камерной системы разработки.
\end{abstract}

Ключевые слова: межходовые целики; междукамерные целики; степень нагружения; математическое моделирование; расчетная высота; скорость оседания.

При ведении горных работ на Верхнекамском месторождении калийно-магниевых солей применяется камерная система отработки с оставлением опорных междукамерных целиков, главной функцией которых является поддержание налегающей толщи пород. В случаях с широкими камерами для обеспечения безопасности ведения работ в момент прохода комбайна оставляют межходовые целики с целью поддержания кровли.

Разрушение межходовых целиков влечет за собой рост нагрузки на междукамерные целики и снижение их несущей способности за счет увеличения величины обрушаемой кровли камер, что в свою очередь ведет к резкому увеличению скорости оседания земной поверхности. Поскольку важными показателями, определяющими опасность нарушения сплошности водозащитной толщи (ВЗТ), являются параметры мульды сдвижения, в частности, максимальные оседания и краевая часть [1], значительный рост оседаний земной поверхности может спровоцировать изменение состояния ВЗТ и негативные последствия для подработанных территорий. В основу расчетов положены методики, включённые в нормативные документы по защите рудников от затопления [2, 3]. В частности, расчетная степень нагружения междукамерных целиков показывает отношение действующей нагрузки к их несущей способности [3]:

$$
C=\xi_{x} \xi_{0} \frac{\gamma l H_{0}}{b k_{f} \sigma_{m}},
$$

где $\xi_{x}$ - коэффициент, учитывающий влияние межходовых целиков, $\xi_{x} \leq 1 ; \xi_{0}$ - коэффициент, учитывающий изменение нагрузки на целики вследствие влияния горнотехнических факторов (пригрузка от солеотвала, опорное давление); $\gamma$ - объемный вес пород; $H_{0}$ - максимальное значение расстояния от земной поверхности до кровли целиков; $b$ - ширина междукамерных целиков; $\sigma_{m}$ - агрегатная прочность пород в массиве; $k_{f}$ - коэффициент формы целиков.

При этом степень нагружения межходовых целиков можно определить следующим образом:

$$
C_{x}=\left(1-\xi_{x}\right) \frac{\gamma l H_{0}}{b_{x} k_{f}^{(x)} \sigma_{m}},
$$

где $b_{x}$ - ширина межходовых целиков; $k_{f}^{(x)}$ - коэффициент формы межходовых целиков.

Коэффициент $\xi_{x}$ рассчитывается по формуле:

$$
\xi_{x}=1-\frac{1}{2}\left(\frac{b_{x}}{b}\right)^{\alpha_{x}}
$$

где $\alpha_{x}$ - параметр аппроксимации; $b_{x}$ - ширина межходовых целиков. 
Параметр $\alpha_{x}$ представляет собой квадратичную зависимость от отношения $\frac{b}{l}[4]$ :

$$
\alpha_{x}=0.4+1.2\left(\frac{b}{l}\right)^{2}
$$

где $l$ - межосевое расстояние.

Межосевое расстояние определяется из выражений:

- без оставления в выработанном пространстве межходовых целиков

$$
l=a+b,
$$

- с оставлением в выработанном пространстве межходовых целиков

$$
l=2 a_{m}+b+b_{x},
$$

где $a$ - расчетная ширина очистных камер; $a_{m}$ - максимальная ширина хода камеры.

Расчетная несущая способность междукамерных целиков оценивается по формуле [4]:

$$
\sigma_{n}=k_{f} \sigma_{m}
$$

Коэффициент формы $k_{f}$ характеризует влияние отношения расчетной ширины целиков к их расчетной высоте на несущую способность целиков:

$$
k_{f}= \begin{cases}\sqrt{2 \lambda}, & \text { при } \lambda \leq 0.5, \\ \beta_{o}\left(1+\beta_{m} \lambda\right), & \text { при } \lambda>0.5,\end{cases}
$$

где $\lambda=\frac{b}{m}$ ( $m$ - высота целика), $\beta_{0}=0.654 ; \beta_{m}=1.06$ - параметры аппроксимации.

Расчетная высота целиков определяется по формуле:

$$
m=m_{0}+\Delta m,
$$

где $m_{0}$ - вынимаемая мощность при отработке пластов.

Расчетное приращение высоты целиков устанавливается из соотношения:

$$
\Delta m=\max \left\{\begin{array}{l}
\Delta m_{o}, \\
m_{o k},
\end{array}\right.
$$

в котором параметр

$$
\Delta m_{o}=\beta_{o k}\left(a-a_{o m}\right),
$$

где $\beta_{o k}$ - коэффициент, учитывающий влияние устойчивости пролета кровли камер на величину приращения расчетной высоты междукамерных целиков; $a_{\text {om }}$-устойчивый пролет кровли камер; $m_{\text {ok }}$ - суммарная мощность коржей, оставляемых в кровле камер.

Значение коэффициента $\beta_{o k}$ определяется из выражения в зависимости от устойчивого пролета кровли:

$$
\beta_{o k}=0.7\left[1.0-\beta_{\text {om }} \sqrt{a_{o m}}\right\rfloor,
$$

где $\beta_{\text {om }}=0.262$ - параметр аппроксимации.

Целью представленных исследований является оценка изменения нарастания оседаний земной поверхности и степени нагружения междукамерных целиков при потере устойчивости межходовых целиков.

\section{Методика математического моделирования}

Математическое моделирование процесса деформирования проводилось в упругопластической постановке для условий плоского деформированного состояния. Для анализа изменения состояния подработанного массива во времени использовался реологический подход, основан- 
ный на математическом описании прогнозных графиков нарастания оседаний земной поверхности [5]. В геомеханической модели подработанного массива целики слагались породами с одинаковыми механическими свойствами. Принципиальная схема расчета представлена на рис. 1 .

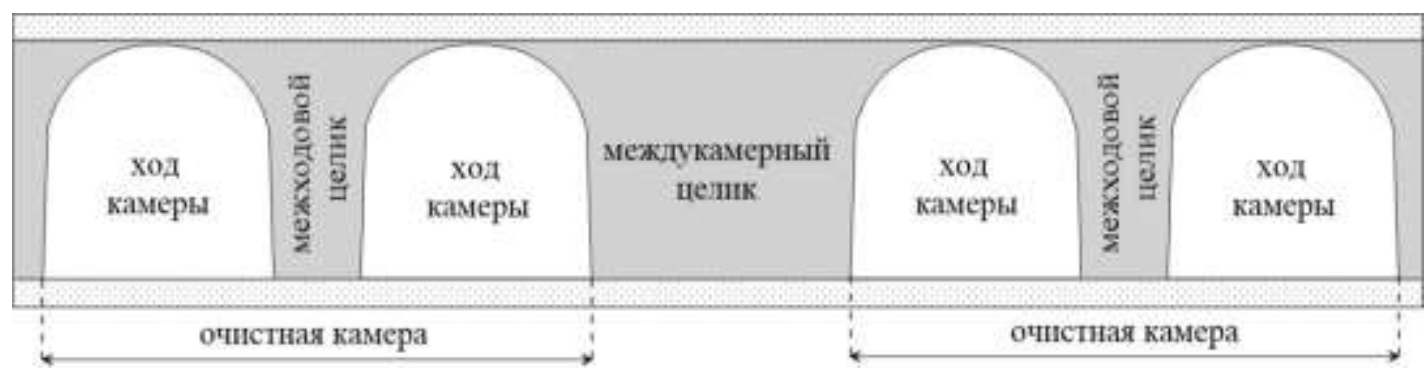

Рис. 1. Камерная система отработки с оставлением межходовых целиков

Как было отмечено ранее, степень нагружения целиков показывает отношение действующей средней нагрузки к их несущей способности. Коэффициент $\xi_{x}(1)$, по своему физическому смыслу, определяет часть нагрузки, приходящейся на междукамерные целики при наличии межходовых целиков. В этом случае нагрузка, приходящаяся на межходовые целики, будет характеризоваться множителем $\left(1-\xi_{x}\right)(2)$. После потери устойчивости межходовых целиков вся нагрузка приходится на межкамерные целики, что приводит к увеличению их степени нагружения. При этом коэффициент $\xi_{x}$ становится равным 1.

a)

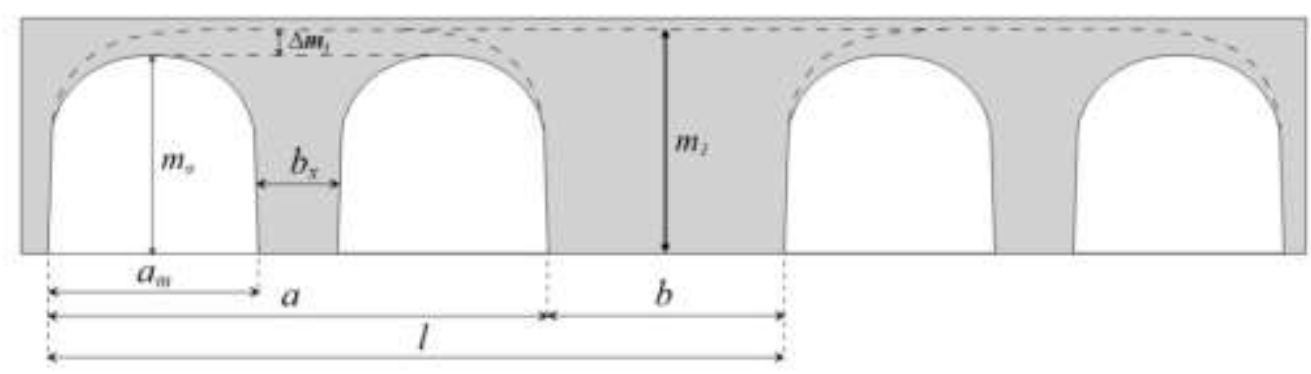

б)

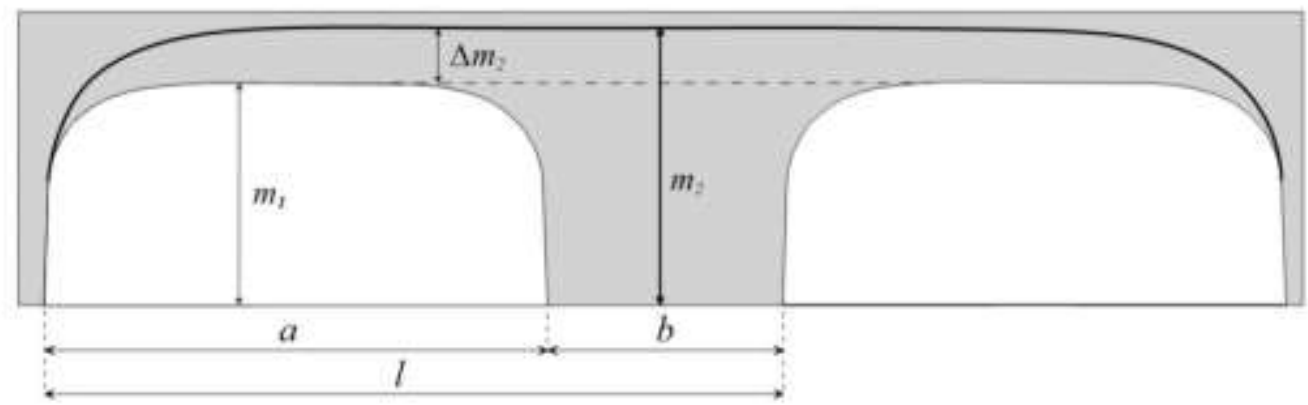

Рис. 2. Схема оценки влияния межходовых целиков на степень нагружения междукамерных целиков

Разрушение межходовых целиков также приводит к изменению несущей способности междукамерных целиков (5) за счет увеличения их расчетной высоты (7). Высота целиков складывается из вынимаемой мощности и расчетного приращения. Расчётное приращение это обрушаемая часть кровли, которая зависит от ширины камеры и устойчивого пролета кровли (9). При сохранении устойчивости межходовых целиков высота рассчитывалась как сумма вынимаемой мощности $m_{o}$ и расчетного приращения $\Delta m_{1}$ (рис. 2 , a), принимая в качестве параметра $a$ ширину хода камеры $a_{m}(9)$. К моменту потери устойчивости межходо- 
вых целиков степень нагружения междукамерных определяется вновь сформированной высотой $\left(m_{2}=m_{1}+\Delta m_{2}\right)$, которая складывается из первоначальной высоты и нового расчетного приращения (рис. 2, б). Последнее пересчитывается, учитывая полную ширину камеры $a$ (9). За счет увеличение высоты, уменышается коэффициент формы $k_{f}(6)$, что ведет к снижению несущей способности междукамерных целиков.

Таким образом, разрушение межходовых целиков сопровождается увеличением степени нагружения междукамерных целиков за счет возрастания нагрузки и уменьшения несущей способности.

\section{Оценка изменения скорости оседания земной поверхности и степени нагружения междукамерных целиков в процессе разрушения межходовых целиков}

Параметры камерной системы отработки с межходовыми целиками представлены на рис. 3. Рассматривался случай отработки пласта КрII с межосевым расстоянием 21.5 м и оставлением междукамерных целиков шириной $b=8$ м. Ширина очистных камер принималась равной $a=13.5$ м, вынимаемая мощность - $m_{o}=5.5$ м. При математическом моделировании ширина межходовых целиков рассматривалась $3 ; 3,5 ; 4$ м, в свою очередь ширина хода камеры менялась по мере изменения ширины межходовых целиков и равнялась 5.25; 5; 4.75 м.

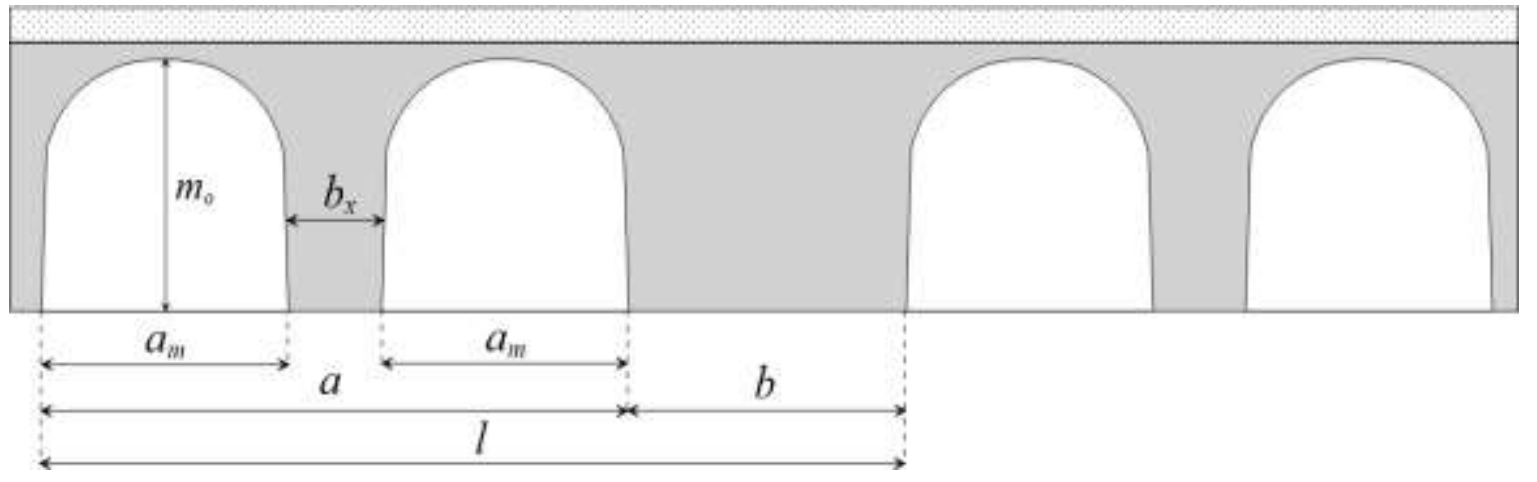

Рис. 3. Параметры отработки

Расчетное значение времени устойчивости межходовых целиков определяется из эмпирической зависимости от их степени нагружения [3]:

$$
\Theta_{x}=\exp \left\{\frac{1-C_{x}}{\beta_{o t}}\right\}^{\alpha_{o t}},
$$

где $\Theta_{x}$ - время сохранения устойчивости межходовых целиков, сутки; $\beta_{o t}, \alpha_{o t}$ - параметры аппроксимации ( $\beta_{o t}=0.065, \alpha_{o t}=1$ - при отсутствии необходимых данных).

Так межходовые целики шириной $3 ; 3,5 ; 4$ м будут сохранять устойчивость в течении 4, 11, 24 лет соответственно. После их разрушения производился перерасчет степени нагружения междукамерных целиков с учетом новой сформированной высоты и повышенной нагрузки.

Результаты расчета изменения степени нагружения междукамерных целиков $C_{K p I I}$ пласта КрII во времени в процессе разрушения межходовых приведены на рис. 4. Как показали расчеты, значительный рост степени нагружения целиков приходится на последний год устойчивости межходовых целиков. Согласно полученным оценкам при $b_{x}$ $=3$ м $C_{\text {КрII }}$ увеличивается с 0.31 до 0.547 в течение 4 лет, $b_{x}=3.5$ м - с 0.296 до 0.544 в течение 11 лет, $b_{x}=4$ м - с 0.283 до 0.542 в течение 24 лет. 


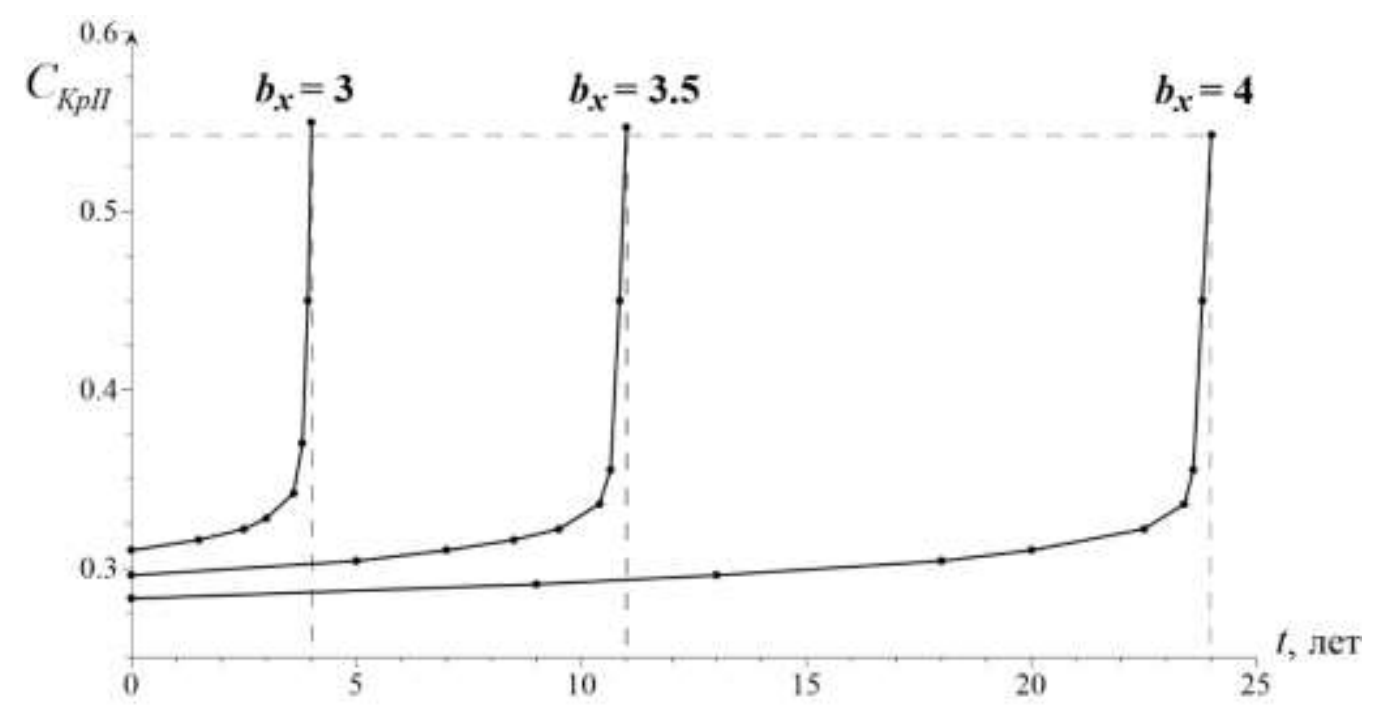

Рис. 4. Изменение степени нагружения междукамерных целиков в процессе разрушения межходовых целиков для $b_{x}=3 ; 3.5 ; 4$ м

Увеличение степени нагружения целиков ведет к росту скорости оседания земной поверхности. Характерный вид нарастания оседаний представлен на рис. 5 (на примере $b_{x}=3.5$ м). Согласно анализу, можно выделить три этапа развития процесса сдвижения. Область I характеризуется относительно медленным увеличением вертикальных смещений во времени, что объясняется сохранением устойчивости межходовых целиков. После потери их устойчивости (область II) наблюдается изменение характера процесса сдвижения, скорость оседаний значительно возрастает. Так, при $b_{x}=3$ м скорость увеличивается в 8 раз, $b_{x}=3.5$ м - 12 раз, $b_{x}=4$ м - 15 раз. С течением времени происходит затухание скоростей оседаний (область III), которое связанно с приближением к значению, соответствующее конечным оседаниям $\eta_{o k}=0.9 m \omega$ ( $\omega$ - коэффициент извлечения руды с пласта).

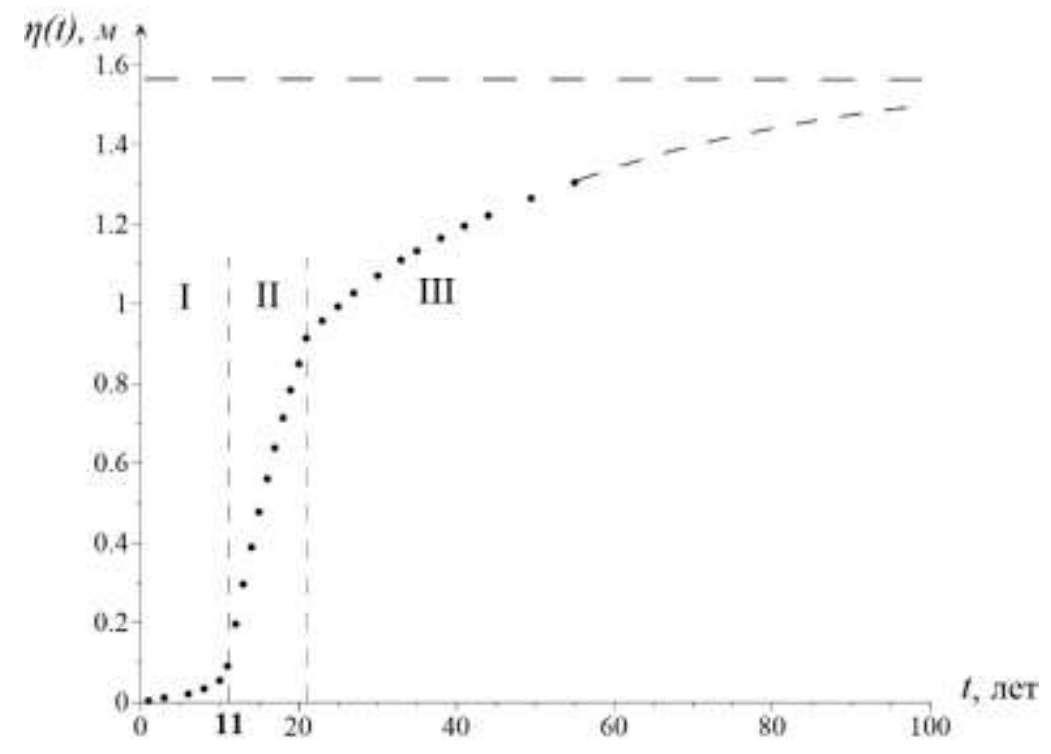

Рис. 5. Нарастание оседаний земной поверхности

Важными показателями, определяющими опасность нарушения сплошности ВЗТ, являются параметры мульды сдвижения [1]. Рост скорости оседания земной поверхности приводит к увеличению максимальных оседаний мульды сдвижения. Это обуслав- 
ливает изменение градиента оседаний (рис. 6), и может негативно сказаться на состоянии В3Т, поскольку участки с высоким градиентом оседаний характеризуются повышенной техногенной нагрузкой на пласты ВЗТ.

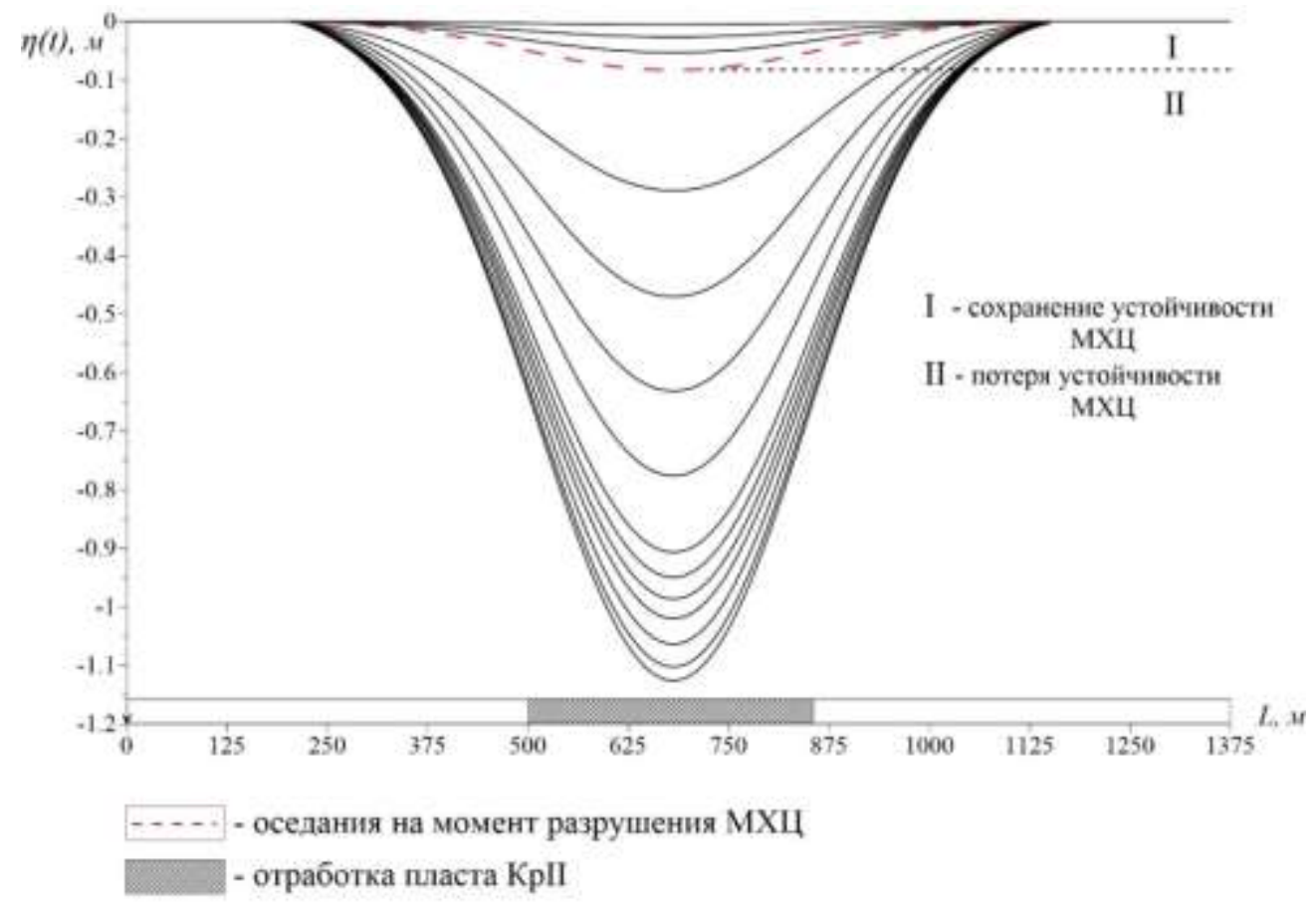

Рис. 6. Изменение мульды сдвижения с течением времени

Таким образом, сохранение устойчивости межходовых целиков характеризуется относительно медленным нарастанием оседаний земной поверхности. Потеря устойчивости межходовых целиков влечет за собой существенный рост степеней нагружения междукамерных целиков и скорости оседания, что в определенных случаях может создать угрозу безопасным условиям подработки.

\section{БИБЛИОГРАФИЧЕСКИЙ СПИСОК}

1 Барях А.А., Самоделкина Н.А. Разработка инженерных критериев нарушения сплошности подработанных толщ / А.А. Барях, Н.А. Самоделкина // Горн. информ.-аналит. бюл. - 2011. - № 4. - С. 12-16.

2 Указания по защите рудников от затопления и охране подрабатываемых объектов в условиях Верхнекамского месторождения калийных солей: утв. ПАО «Уралкалий», ЗАО «Верхнекамская калийная компания», ООО «ЕвроХим-Усольский Калийный комбинат». - введ. в действие 30.03.2017 в ред. 2014 г. Пермь; Березники, 2014. - 130 с.

3 Методические рекомендации к «Указаниям по защите рудников от затопления и охране подрабатываемых объектов в условиях Верхнекамского месторождения калийных солей»: введ. в действие с 30.03.2017 г., в ред. 2014 г. - Пермь; Березники, 2014. -

4 Разработка методических рекомендаций по геомеханическому обеспечению безопасности горных работ на рудниках ОАО «Сильвинит»: отчет о НИР по договору № 11/05 с ОАО "Сильвинит" / ГИ УрО РАН; рук. А.А. Барях; отв. исполн. Н.А. Самоделкина. - Пермь, 2005. - 17 с.

5 Барях А.А. Об одном подходе к реологическому анализу геомеханических процессов / А.А. Барях, Н.А. Самоделкина // Физико-технические проблемы разработки полезных ископаемых. - 2005. - №6. - С. 32-41.

6 Зенкевич О. Метод конечных элементов в технике / О. Зенкевич. - М.: Мир, 1975. - 541 с.: ил.

7 Барях А. А., Лобанов С. Ю., Ломакин И. С. Анализ изменения степени нагружения междукамерных целиков во времени на Верхнекамском месторождении солей. // // Физико-технические проблемы разработки полезных ископаемых. - 2015. - № 4. - С. 70-82.

8 Малинин Н.Н. Прикладная теория пластичности и ползучести. - М.: Машиностроение, 1975. - 400 с. 